\title{
The right contextual information determining the success of communication on translation
}

\author{
Zera $\mathbf{Z u}^{1}$
}

\section{ARTICLE INFO}

Received: 9 December 2020

Revised: 18 January 2021

Accepted: 27 February 2021

\section{KEYWORDS}

communication,

comprehension,

information,

receptor language,

translation.

\begin{abstract}
As relevance theory shows, the success of communication crucially depends on the right contextual information being highly accessible at the right time. Thus it is not sufficient that this information is physically available somewhere in the receptor language; to become effective for comprehension it must be highly accessible mentally to the reader or hearer at the time when it is needed. Thus while it is true in a general way that the translation of Old Testament portions is important because they provide background information necessary for understanding the New Testament, for it to be profitable for the comprehension of a particular New Testament passage, readers must be able to access in their minds just those pieces of information from the Old Testament that are relevant to this specific passage.
\end{abstract}

Copyright $\left({ }^{\circ} 2021\right.$ by The author(s). This is an open access article distributed under the terms of the Creative Commons Attribution (CC BY 4.0), which permits unrestricted use, distribution, and reproduction in any medium, as long as the original authors and source are cited. No permission is required from the authors or the publishers.

Correspondence:

$\mathrm{Zu}, \mathrm{Z}$.

而 Amazon.com, Inc., Seattle, United States, Phone: +1 206-922-0880

Dzerazu@amazon.com 


\section{INTRODUCTION}

Note that this requires more than just familiarity with those portions; it requires the readers' ability to select the particular pieces of information needed for the NT passage in question out of a sizeable body of information. Information from the Old Testament can lead to all sorts of interpretations, some of which may be valid but not part of the intended meaning of the passage, some of which will be quite wrong, and only some of which will lead to its intended interpretation [1][2].

In the original communication situation the "synchronisation" of context selection was controlled by the accessibility structure of the mutual cognitive environment of author and audience. In cross-cultural, secondary communication situations this common accessibility structure rarely exists naturally, but most often must be created by appropriate means. This, then, is another essential part of an adequate strategy for biblical literacy [3].

\section{MATERIALS AND METHODS}

Another closely related set of issues biblical literacy needs to address is that of effort and motivation. According to the insights of modern communication studies, processing effort plays a key role in communication; human beings tend to be very economically minded when it comes to the expenditure of effort: they have a very strong tendency to avoid unnecessary effort. On the one hand, this tendency is extremely valuable: it imposes crucial constraints on the comprehension process without which communication would hardly work at all [4][5]. On the other hand, it also limits what is communicable to a particular group of people: people will not process just any information offered to them; they will invest effort only if and as long as they are convinced that it is worth their while. Thus one of the challenges faced in biblical literacy is how to motivate people sufficiently to process the background information offered.

\section{RESULTS AND DISCUSSIONS}

Generally speaking, motivation can be of two kinds: the desire for positive experiences or the fear of negative ones - in the common idiom, the carrot and the stick. In the case of biblical literacy, generally speaking, only the carrot is available. Now there is a kind of "carrot" that is intrinsic to communication: it consists in the experience of relevance, the reward of cognitive effects, and according to current insights, it is the central factor that makes human communication work [6]. One might also describe it as the satisfaction of comprehension, the satisfaction one experiences when one feels that one has understood the other.

While the satisfaction of comprehension is a necessary condition for successful communication, it alone may not be sufficient for sustaining the processing effort necessary for larger chunks of information. In real life, information from different kinds of sources frequently competes for our attention, and it is usually the one that promises the greatest benefits that is the winner. In this competition, often factors other than cognitive benefits can exert a strong influence. After all, communication is not just an end in itself. The information exchange it facilitates can affect us and our lives in innumerable ways. It can help us build and maintain social relationships, it can help us to satisfy emotional or physical needs, and so forth [7][8]. Any of these factors can affect people's motivation, and either strengthen or distract from their interest in translated Scriptures.

This fact seems to be borne out by Dye's research into factors determining the spiritual impact of Bible translations. He found that "the single most important thing that a translator can do to bring response is to apply the Good News to personal needs, hopes and problems as frequently as possible. ...In the fifteen programmes studied, more than half of the variation noted in spiritual results was related to how well this one thing was done" [9]. Dye called this "the principle of 'Personal Relevance" and expressed it more formally as follows: "People respond to the gospel in proportion to their conviction that God and his word are relevant to the concerns of daily life" [10].

Thus the motivational factor needs to be carefully considered in the design of biblical literacy programmes. It is not enough to test whether the materials provide the information necessary for adequate comprehension when used, though this is important. One has to also assess whether or under what circumstances receptors actually use these materials. Bible background materials may be very good in covering all the ground necessary; however, if they require too much effort or offer too little benefit, they will remain unused and hence be of no help for comprehension [11].

In many situations, separate tests may have to be run for different groups of people; for example, motivational factors among church members may be quite different from those outside. Cinema is widely known as the seventh art and its visual authenticity and persuasive power requires adequate study and evaluation which, in its turn, will elevate cinematic tastes of the general public. In connection with this the importance of the translators "e attempts in rendering English filmonyms into Russian must not be underestimated [12]. The

Vol. 15 | No. 1 | 2021 | Pages: 39-43 
problem of the filmonym translation is especially important in the era of globalisation, when international competition is on the rise and the language norm is often violated to suit the economic needs of the box-office. The problem of translation in films is very topical since it is viewed as the interaction between two cultures and the reflection of foreign ideas, views and language in the home domain. The theoretical foundations of the study of filmonyms se translation is based on the theory of translation, film text semiotics, discourse theory and the study of cultural interaction [13][14]. The object of study incorporates more than five hundred film titles in English, which had been differently translated in the Russian film distribution.

The method of typological synchronous comparison is used in the analysis of localized filmonyms. It allows us to compare similarities, differences and peculiarities of filmonym translation in the cultural interaction between Russian and English languages. The method of functional analysis takes into account the degree of suitability of the translation for the home culture. In the classical theory of translation its main subject is viewed as inter-linguistic transformation of the source text into the secondary text (translatum) where the interpreteres ${ }^{\text {ee }}$ role is to render the conceptual essence of the text adequately [15]. The translation is expected to be equivalent to the original text, while the distancing from the poetic license should be maximized. There are four basic tools in the arsenal of the interpreter: transposition, change, addition and omission [16]. Russian scholar Ya. Retsker widens the circle of lexical transformations: specialisation, generalisation, defferentiation of meaning, antonymic and compensatory translation [Retsker 1974]. Traditional approach postulates that transcoding of the language imagery should preserve the wholesome nature of the information enclosed in the source text [17].

As it will be shown in the paper, the notion of careful translation is becoming obscured. N. Garbovsky states, that «...in the process of translation there is no place for the transformation of the subject, as in its strict sense any transformation entails the elimination of the primary condition, the form of the subject etc., and there is subsequent replacement of the subject by other forms. In the translation the subject, the source text is left unchanged. As a result of translation a new art form, a new subject is created. Therefore, there is no possibility for neither transformational, not deformational changes in translation» [18]. In the new light, there is a "gap", a refusal from rendering the exact sense in favour of the cultural specifics of the receiving culture. The recognition always goes hand in hand with the explanation thus making the cultural exactitude a variable entity. As a result, the leading trend in filmonym translation is to interpret and reconceptualise the subject, which entails the refusal to deal with the essence of the subject in favour of personalized ad hoc remakes.

The content of the film often proves to be irrelevant for the filmonym ${ }^{\text {ee }}$ translation. The system of distribution and the backlist of films in circulation play an important role in the choice of the new title for a foreign film. The algorithm of the film title ${ }^{e e} \mathrm{~s}$ choice is very complex and involves advertisers, chief executives, directors, all of whom are able to offer their variants. Naming stages include «market research, approval of title requirements, name generation, preliminary choice, test group poll, and final choice. Step by step the abundance of offers makes place for something suitable» [19].

It is clear that not only translators have thir say in the choice, but it must be remembered that a good interpreter retains a mega-concept in the new film title, while a careless one, on the contrary, indulges into trivial word-for-word rendering. In the printed television programme «Saint-Petersburg Viewer» №36 published on the $16^{\text {th }}$ of September 2018 the film rubric commentator Alexander Chekulaev was asked about the overseas control over filmonyms translation. This is what he said: «...big film studios often control the translation and affect the choice of important projects, but nobody cares about the majority of films, if Russians believe that "an unauthorised" adapted film title would make a lot of money - that will do» [20]. Continuous monitoring of the localization of filmonyms in the XX - XXI century distribution has allowed the author of the paper to collect more than 500 film titles with inequivalent Russian translation. Futher on the following trends will be discussed in detail: dramatisation, jargonizm, infernality, discursiveness, depersonification, explanation, misogyny, negativism, minimal word play and forenization.

A number of significant translations were chosen from the modern sources (in the list of filmonyms we first give the Russian transliterated film title, next its translation into English and finally its original English title): "Bol'shaja Igra (Big Game)» < (Molly's Game) (2017), "Bol'shoj Chelovek (Big Man)» < (Crossing the Line) (1990), "Velikij Uravnitel' (Great Equalizer 2)» 〈 (The Equalizer 2) (2018), «Opasnyj Biznes (Dangerous Business)» 〈 (Gringo) (2018), «Posledniaja Nadezhda Chelovechestva (The Last Hope of Humanity)» < (Against The Dark) (2009), «Samyj Pjanyj Okrug v Mire (The Drunkest District in the World)» 〈(Lawless) (2012) etc.

Cinema is gaining more and more power over the minds of people. Dramatising filmonyms use a number of means to make a film ${ }^{\text {ee }}$ title attractive - hyperbole (to name a character a great person), romantisation (to elevate the essence of the illegal activity), mystification (to make the film "s essence look weird). Epithets like ,dangerous ${ }^{e e}$, ,new ${ }^{e e}$, ,the last ${ }^{\text {ee }}$ and „,very are used to intensify the translation"s emotional charge. The 
film industry is skilfully using the publices naive expectation of the grand miracle. Skilful interpreters use this desire magnifying the suggestive power of the film ${ }^{\text {ee }}$ s title.

A row of modern film titles are chosen from the modern sources. In the translation interpreters used omission and conceptual substitution accompanied by the pejorative shading of meaning (in the list of filmonyms we first give the Russian transliterated film title, next its translation into English and finally its original English title): «Bezbashennaja Pulja (Crazy Bullet)» < (Hollow Point) (2019), «Boss-Molokosos (BossMilksucker)» 〈 (The Boss Baby) (2017), «Klevyj Paren' (Cool Guy)» く (Bowfinger) (1999), «Krutoj i Tsypochki (The Cool Man and the Chicks)» < (Man of the House) (2005), "Lesnaja Bratva (The Forest Mob)» < (Over the Hedge) (2006), «Podvodnaja Bratva (Deepsea Mob)» < (Shark Tale) (2004) etc.

The cinematic art as the youngest of arts is rightly addressing younger generations, aged 16 to 25 , those who are different from the traditions and norms established in the polite society. Youngsters demand acceptance of their lifestyle and values, their linguistic self-expression finds vent in jargonisms like „,coole ${ }^{\text {ee }, \text { crap }^{e e} \text {, „,chick }}{ }^{e e}$ etc. Localisation serves as a useful mechanism of fixating these topical trends. Although the trend for liberalization of the linguistic means is obvious here, the norm is being violated in favour of bright, expressive means acceptable in non-official communication, which is full of humour, irony and even sarcasm. The downside of such linguistic liberalization is the ease with which personal bounds are violated, disregard for norms of modesty and political correctness.

Let us enumerate the most revealing examples of this category found in the modern edition. The technique of demonisation was used in the following translated titles (in the list of filmonyms we first give the Russian transliterated film title, next its translation into English and finally its original English title): «Adskaja Kukhnja (Hell's Kitchen)» < (Paradise Alley) (1978), "Adskij Smerch (Hell's Twister)» < (Fire Twister) (2015), "Djavol'skij Osobnjak (Devil's Mansion)» < (Cold Creek Manor) (2003), «Pazmanskij Djavol (Pazman Devil)» < (Bleed for This) (2016), «Prizraki (Ghosts)» < (Wind Chill) (2007), «Furgon Smerti (Death Vagon)» 〈 (The Toybox) (2018) etc.

Infernality of translation in this category goes hand in hand with morbiality as well as the tendency for occult studies and back morals. Modernity is characterised by the aggressiveness in the day-to-day and parliamentary communication. The abovementioned translated film titles are aimed at evoking the sense of shock in the viewer. The shock is followed by the communicative "glitch" (I can"t believe it!) and the ensuing attempts to interpret the essence of the shocking title. Social psychologist L. Festinger offered the theory of the communicative imbalance underscoring the existence of «...hindered understanding as a result of the imbalance in the models of the world». No big surprise that, even negative qualities like ugliness, vice or passion are regarded as able to attract interest in the viewer. As a result even negative emotion of fear, shame and morbid curiosity motivate people to choose the film for watching - anything goes, anything for a box-office - this might be the slogan of the modern film industry.

\section{CONCLUSION}

The material under study had demonstrated that the topic of filmonyms translation is very modern, innovational and full of controversial aspects. Therefore the interest to translation in film will grow in the sphere of international film industry, where questions of authors ${ }^{\text {ee }}$ rights and linguistic norms arise on a regular basis. Very often the interpreter"s thought takes an easy path of replacement, change and recombination without dealing with the film ${ }^{\text {ee }}$ ideologically and artistically tricky subject matter. There ees St. Hieronimus oath, which states that the interpreter should be understanding, truthful, clear, reliable - these requirements are often violated in filmonyms ${ }^{\text {ee }}$ translation. Loyalty to the language transforms into the loyalty to those who dictate the final variant of the filmonym ${ }^{\text {ec }} \mathrm{s}$ translation: clients, producers and distributors. E. Hirsch had once described understanding as a picnic where authors bring words and readers bring meanings: "It has been said of Boehme that his books are like a picnic to which the author brings the words and the reader the meanings" [Hirsch 1967]. In connection with the translation in movies it seems that modern viewers are promised a posh banquet, but are fed with low-quality fast food. Those responsible for decision-making take a viewer for a fun-loving xenophobic mediocrity, offering us run-of-the-mill low quality translated matter. The situation should change, as the author of the article strongly believes, in the direction of justified cultural appropriation. The translators must pay more careful attention to the standards and norms of the receiving culture.

\section{Conflict of Interest Statement}

The authors declare no conflicts of interest related to the material presented in this article.

\section{REFERENCES}

[1] Barua, S., Ahmed, M. U., Ahlström, C., \& Begum, S. (2019). Automatic driver sleepiness detection using EEG, EOG and contextual information. Expert systems with 
applications, 115, https://doi.org/10.1016/j.eswa.2018.07.054

$121-135$

[2] Bublatzky, F., Kavcığlu, F., Guerra, P., Doll, S., \& Junghöfer, M. (2020). Contextual information resolves uncertainty about ambiguous facial emotions: Behavioral and magnetoencephalographic correlates. NeuroImage, 215, 116814. https://doi.org/10.1016/j.neuroimage.2020.116814

[3] Callejas, Z., \& Lopez-Cozar, R. (2008). Influence of contextual information in emotion annotation for spoken dialogue systems. Speech Communication, 50(5), 416433. https://doi.org/10.1016/j.specom.2008.01.001

[4] Chun, M. M. (2000). Contextual cueing of visual attention. Trends in cognitive sciences, 4(5), 170-178. https://doi.org/10.1016/S1364-6613(00)01476-5

[5] Dror, I. E., Charlton, D., \& Péron, A. E. (2006). Contextual information renders experts vulnerable to making erroneous identifications. Forensic science international, 156(1), 74-78. https://doi.org/10.1016/j.forsciint.2005.10.017

[6] Jiang, K., Yin, H., Wang, P., \& Yu, N. (2013). Learning from contextual information of geo-tagged web photos to rank personalized tourism attractions. Neurocomputing, 119, 17-25. https://doi.org/10.1016/j.neucom.2012.02.049

[7] Ko, Y., \& Seo, J. (2008). An effective sentence-extraction technique using contextual information and statistical approaches for text summarization. Pattern Recognition Letters, 29(9), https://doi.org/10.1016/j.patrec.2008.02.008

[8] Luvizon, D. C., Tabia, H., \& Picard, D. (2019). Human pose regression by combining indirect part detection and contextual information. Computers \& Graphics, 85, 1522. https://doi.org/10.1016/j.cag.2019.09.002

[9] Mahata, N., Kahali, S., Adhikari, S. K., \& Sing, J. K. (2018). Local contextual information and Gaussian function induced fuzzy clustering algorithm for brain MR image segmentation and intensity inhomogeneity estimation. Applied Soft Computing, 68, 586-596. https://doi.org/10.1016/j.asoc.2018.04.031

[10] Mayes, A. R., Meudell, P. R., \& Pickering, A. (1985). Is organic amnesia caused by a selective deficit in remembering contextual information?. Cortex, 21(2), 167202. https://doi.org/10.1016/S0010-9452(85)80026-5

[11] Melgani, F., \& Serpico, S. B. (2002). A statistical approach to the fusion of spectral and spatio-temporal contextual information for the classification of remotesensing images. Pattern Recognition Letters, 23(9), 10531061. https://doi.org/10.1016/S0167-8655(02)00052-1

[12] Osborne, N. K., \& Taylor, M. C. (2018). Contextual information management: an example of independentchecking in the review of laboratory-based bloodstain pattern analysis. Science \& Justice, 58(3), 226-231. https://doi.org/10.1016/j.scijus.2018.01.001

[13] Osborne, N. K., Woods, S., Kieser, J., \& Zajac, R. (2014). Does contextual information bias bitemark comparisons?. Science \& Justice, 54(4), 267-273. https://doi.org/10.1016/j.scijus.2013.12.005

[14] Ramesh, B., Xiang, C., \& Lee, T. H. (2015). Shape classification using invariant features and contextual information in the bag-of-words model. Pattern Recognition, 48(3), 894-906. https://doi.org/10.1016/j.patcog.2014.09.019

[15] Sharot, T., \& Yonelinas, A. P. (2008). Differential timedependent effects of emotion on recollective experience and memory for contextual information. Cognition, 106(1), 538-547. https://doi.org/10.1016/j.cognition.2007.03.002

[16] Simons, J. S., Owen, A. M., Fletcher, P. C., \& Burgess, P. W. (2005). Anterior prefrontal cortex and the recollection of contextual information. Neuropsychologia, 43(12), 1774-1783.

https://doi.org/10.1016/j.neuropsychologia.2005.02.004

[17] Stuckens, J., Coppin, P. R., \& Bauer, M. E. (2000). Integrating contextual information with per-pixel classification for improved land cover classification. Remote sensing of environment, 71(3), 282296. https://doi.org/10.1016/S0034-4257(99)00083-8

[18] Tao, C., Qi, J., Li, Y., Wang, H., \& Li, H. (2019). Spatial information inference net: Road extraction using roadspecific contextual information. ISPRS Journal of Photogrammetry and Remote Sensing, 158, 155-166. https://doi.org/10.1016/j.isprsjprs.2019.10.001

[19] Volpi, M., Tuia, D., Bovolo, F., Kanevski, M., \& Bruzzone, L. (2013). Supervised change detection in VHR images using contextual information and support vector machines. International Journal of Applied Earth Observation and Geoinformation, 20, 77-85. https://doi.org/10.1016/j.jag.2011.10.013

[20] Xia, X., Togneri, R., Sohel, F., \& Huang, D. (2018). Random forest classification based acoustic event detection utilizing contextual-information and bottleneck features. Pattern Recognition, 81, 1-13. https://doi.org/10.1016/j.patcog.2018.03.025 